\title{
Pulmonary hypertension complicating pulmonary fibrosis: bad and ugly, but good to treat?
}

\author{
Steven D Nathan
}

Pulmonary hypertension (PH) often complicates the course of patients with many forms of advanced lung disease, including those with pulmonary fibrosis. ${ }^{1}$ There is a growing appreciation of the association of $\mathrm{PH}$ with greater functional impairment, higher oxygen needs and poorer outcomes. $^{2}$ What remains unknown is how much of a role $\mathrm{PH}$ has in these detrimental outcomes or whether it is an adaptive phenomenon and a surrogate for other untoward consequences of the parenchymal

Correspondence to Dr Steven D Nathan, Advanced Lung Disease and Transplant Program, Department of Medicine, Inova Heart and Vascular Institute, Falls Church, VA 22042, USA; steven.nathan@inova.org lung disease. Indeed, it is conceivable that, at its outset, $\mathrm{PH}$ is adaptive or reactive and in some patients evolves to a maladaptive phenomenon. This two-compartment concept is central to the notion of disproportionate $\mathrm{PH}$, which is often spoken about but remains ill-defined. By implication, $\mathrm{PH}$ is 'disproportionate' when it is felt unlikely to be explained by the extent of the parenchymal lung disease alone, is functionally limiting, and/or is the primary driver of outcomes. This inevitably leads to the question of whether or not such patients might benefit from pulmonary vasoactive medications.

With the increasing number and availability of approved agents to treat group 1 pulmonary arterial hypertension (PAH), there has been growing interest and curiosity in treating group $3 \mathrm{PH}$. When weighing the appeal of this strategy, it is important to remember that prior advances in medicine have been punctuated with interventions that made biological and physiological sense, but did not pan out, and in some cases inflicted more harm than good. Nonetheless, select studies addressing the treatment of $\mathrm{PH}$ in idiopathic pulmonary fibrosis (IPF) have provided signals suggestive of improved outcomes. ${ }^{3}$ The largest of these studies was the Step-IPF Study, which was enriched for IPF patients with $\mathrm{PH}$ through the inclusion criterion of a single breath-diffusing capacity of $<35 \%$ of predicted. Although this study was negative based on the chosen primary end point of a $20 \%$ improvement in the 6 min walk (6MWT) distance, there were improvements in a host of secondary outcomes, including quality of life and measures of gas exchange. There was also a signal of a possible mortality benefit that came tantalisingly close to being significant. ${ }^{3}$ A subsequent subgroup analysis of those 
patients with right ventricular dysfunction did demonstrate substantially better preservation of the $6 \mathrm{MWT}$ distance, as well as improvements in quality of life in the active treatment arm. ${ }^{5}$

The study by Saggar et al builds on this concept further by studying pulmonary fibrosis patients with advanced $\mathrm{PH}$, defined by a mean pulmonary artery pressure $(\mathrm{mPAP}) \geq 35 \mathrm{~mm} \mathrm{Hg} .{ }^{6}$ Patients in this study also had evidence of significant right-sided cardiac dysfunction. Although the number of patients studied was relatively small, it is encouraging that a salutary response to $\mathrm{PH}$ therapy across multiple domains was demonstrated. A number of issues have been raised and will need clarification in future, larger, prospective studies. Most patients with $\mathrm{PH}$ secondary to pulmonary fibrosis have pulmonary pressures that are only mildly elevated, while in this study all patients had advanced $\mathrm{PH}$. The range of pressures studied approaches that of patients in PAH clinical trials where the mean mPAP has invariably been in the $40-50 \mathrm{~mm} \mathrm{Hg}$ range. Choosing the correct patient phenotype in the context of pulmonary fibrosis might be critical to the successful outcome of any $\mathrm{PH}$ intervention. It makes intuitive sense that the higher the pressures, the more likely the therapy will result in measurable improvements. So, should only those patients with a $\mathrm{mPAP} \geq 35 \mathrm{~mm} \mathrm{Hg}$ be enrolled in any future clinical trials of group 3 PH? While the strategy of choosing higher pressure thresholds might enrich the population for a successful trial, this has to be balanced against fewer patients who will meet the study threshold for inclusion. Indeed, when choosing a suitable patient population for future clinical trials, should it be the mPAP that determines inclusion or should another variable indicative of a failing right ventricle define the study population? It is well known in $\mathrm{PAH}$ that right ventricular decompensation determines outcomes, and it is conceivable that a similar pathophysiological scenario holds true for the PH of pulmonary fibrosis. Therefore it might be important not to be anchored to one pressure threshold in defining the patient population.

Another issue raised is which end point(s) to use in any future study of $\mathrm{PH}$ in pulmonary fibrosis. Although the investigators did use the $6 \mathrm{MWT}$ as an end point, its validity and use as a surrogate for subsequent outcomes has recently been questioned. ${ }^{7} 8$ In the present study, improvements in the 6MWT distance were accompanied by parallel improvements in haemodynamics and quality-of-life measures. Together with prior data demonstrating an association between decrements in distance and outcomes in IPF, this does suggest that the $6 \mathrm{MWT}$ has a role in future pulmonary fibrosis-related $\mathrm{PH}$ studies. ${ }^{9}$ However, there are multiple open questions about how best to implement and improve its performance in the context of such studies. What is the best walk instruction? How should supplementary oxygen be implemented and what are the 'stop' criteria for excessive desaturation? How many tests should be performed and which ones should be used for analysis? ${ }^{10} 11$ Should the primary analysis be the mean (or median) change between groups or a categorical analysis informed by an estimate of the minimally important difference? ${ }^{12}$ Should it be the distance attained or another novel $6 \mathrm{MWT}$-derived variable such as the pulse rate recovery ? $^{13}{ }^{14}$ In the present study, most of the patients were transplanted or died, which underscores the poor outcome associated with pulmonary fibrosis and advanced PH. So do we even need the $6 \mathrm{MWT}$ in the context of a prognosis so poor that a mortality study might be feasible? It is probably wise to anticipate that a pure mortality study would be difficult to recruit and therefore mortality might be better integrated within the construct of a broader clinical worsening end point. Lastly, is there something specific to the study drug, treprostinil, or would any $\mathrm{PAH}$ therapy be effective?

Where do we go from here? A study such as this might provide a platform for others to adopt off-label treprostinil or other $\mathrm{PAH}$ therapies in patients with pulmonary fibrosis-related $\mathrm{PH}$. One could argue that this might be reasonable in select, fully informed patients and under the stewardship of an experienced interstitial lung disease and $\mathrm{PH}$ centre. However, we need to learn from mistakes of old, where in our quest and zest to help patients, harmful therapies were instituted on the basis of small case series. Nowhere is this more apparent than in IPF, where, after two decades of widely adopted use, therapy with azathioprine and steroids (with or without $\mathrm{N}$-acetylcysteine) was only recently demonstrated to result in worse outcomes. ${ }^{15}$ Rather than encourage the use of PAH medications for pulmonary fibrosis, this study has started the clock and should serve as a call to arms for well-conceived studies with 'good' or smart targeting of the 'bad' that all too often accompanies the 'ugly'.

Competing interests SDN has consulted for Bayer, Gilead Sciences and United Therapeutics about studies addressing the treatment of group $3 \mathrm{PH}$. He is currently the Principal Investigator for a Bayer study evaluating the treatment of $\mathrm{PH}$ in the idiopathic interstitial pneumonias.
Provenance and peer review Commissioned internally peer reviewed.

To cite Nathan SD. Thorax 2014;69:107-108.

Received 12 December 2013

Accepted 13 December 2013

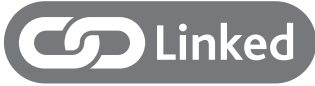

http://dx.doi.org/10.1136/thoraxjnl-2013-204150

Thorax 2014;69:107-108.

doi:10.1136/thoraxjnl-2013-204964

\section{REFERENCES}

1 Nathan SD, Noble P, Tuder R. Idiopathic pulmonary fibrosis and pulmonary hypertension: connecting the dots. Am J Respir Crit Care Med 2007;175: 875-80.

2 Lettieri CJ, Nathan SD, Barnett S, et al. Prevalence and outcomes of pulmonary arterial hypertension in idiopathic pulmonary fibrosis. Chest 2006;129: 746-52.

3 Zisman DA, Schwarz M, Anstrom KJ, et al. A controlled trial of sildenafil in advanced idiopathic pulmonary fibrosis. N Engl J Med 2010;363:620-8.

4 Ghofrani HA, Wiedemann R, Rose F, et al. Sildenafil for treatment of lung fibrosis and pulmonary hypertension: a randomised controlled trial. Lancet 2002;360:895-900.

5 Han MK, Bach DS, Hagan PG, et al. Sildenafil preserves exercise capacity in patients with idiopathic pulmonary fibrosis and right-sided ventricular dysfunction. Chest 2013;143:1699-708.

6 Saggar R, Khanna D, Vaidya A. Changes in right heart hemodynamics and echocardiographic function in an advanced phenotype of pulmonary hypertension and right heart dysfunction associated with pulmonary fibrosis. Thorax 2014;69: 123-29.

7 Gabler NB, French B, Strom BL, et al. Validation of 6-minute walk distance as a surrogate end point in pulmonary arterial hypertension trials. Circulation 2012;126:349-56.

8 McLaughlin VV. Has the 6-Min walk distance run its course? Chest 2012:142:1363-4.

9 Du Bois RM, Albera C, Bradford WZ, et al. 6-minute walk test distance is an independent predictor of mortality in patients with idiopathic pulmonary fibrosis. Eur Respir J Published Online First: 5 Dec 2013. doi:10.1183/09031936.00131813

10 Weir NA, Brown AW, Shlobin OA, et al. The influence of alternative instruction on the six minute walk test distance. Chest 2013;144:1900-5.

11 Dolmage TE, Hill K, Evans RA, et al. Has my patient responded? Interpreting clinical measurements such as the 6-minute-walk test. Am J Respir Crit Care Med 2011;184:642-6.

12 Du Bois RM, Weycker D, Albera C, et al. Six-minutewalk test in idiopathic pulmonary fibrosis: test validation and minimal clinically important difference. Am J Respir Crit Care Med 2011;183:1231-7.

13 Swigris JJ, Swick J, Wamboldt FS, et al. Heart rate recovery after 6-minute walk test predicts survival in patients with idiopathic pulmonary fibrosis. Chest 2009;136:841-8.

14 Minai OA, Gudavalli R, Mummadi S, et al. Heart rate recovery predicts clinical worsening in patients with pulmonary arterial hypertension. Am J Respir Crit Care Med 2012;15:400-8.

15 The Idiopathic Pulmonary Fibrosis Clinical Research Network. Prednisone, azathioprine, and $\mathrm{N}$-acetylcysteine for pulmonary fibrosis. N Engl J Med 2012:366:1968-77. 